\title{
Five years of development in pursuing excellence in quality and global impact to become the first journal in STEM education covered in $\mathrm{SSCl}$
}

Yeping Li

\begin{abstract}
With the completion of its first five publication cycle years (August 2014 to July 2019), the International Journal of STEM Education has made great progress with its commitments to pursue excellence in quality and worldwide impact. In this editorial, I specifically share the journal's achievements since August 2018 in obtaining Scopus's CiteScore and for being included in Web of Science's Social Sciences Citation Index (SSCl), which reflect the journal's continued growth with on-going strong support from researchers and readers internationally.
\end{abstract}

Keywords: Impact, Quality, Readership, Scopus, SSCI journal, STEM education

\section{Introduction}

In the 2018 editorial (Li, 2018a), I summarized the journal's publications over its first four publication cycle (PC) years from August 2014 to July 2018. The steady growth in publications has enabled the journal to serve as a gathering place for international researchers and readers to share their scholarly work in science, technology, engineering and mathematics (STEM) education. By the end of July 2018, the journal was already being included in Scopus by Elsevier and in Web of Science's Emerging Sources Citation Index (ESCI) by Clarivate Analytics.

In October 2019, the International Journal of STEM Education was selected for coverage, together with other 14 journals, in Web of Science's Social Sciences Citation Index (SSCI). This elevation let the International Journal of STEM Education become the very first journal in STEM education ${ }^{1}$ worldwide for being included in SSCI. It took the journal five publication cycle years from $\mathrm{Au}$ gust 2014 to July 2019 to gain this recognition, which

\footnotetext{
${ }^{1}$ Journals denoted by the acronym of STEM, not including those single-disciplinary or other multi-disciplinary education journals that may focus on two- or three-disciplinary in STEM.
}

Correspondence: yepingli@tamu.edu

Texas A\&M University, College Station, TX 77843-4232, USA practically makes the journal one of the fastest in reaching this status among all the educational journals in science, technology, engineering, and mathematics published by Springer since a journal's inception. The journal's achievements reflect very well not only the quality and impact of its publications, but also the rapid development of STEM education as an international field (Li, 2018a; Li, Froyd \& Wang, 2019).

In the following sections, I will summarize recent progress, publication status and trends of the International Journal of STEM Education, and discuss its contributions to the field of STEM education.

\section{Recent progress reflected in the journal's new performance measures}

Since August 2018, the journal has continued to make a lot of progress in multiple fronts. As the journal's performance continues to be monitored by various indexing services, its impact and value can certainly be reflected in the related measures from reputable and important indexing services. Specifically, the journal received its first Scopus's CiteScore (CS) of 2.40 from Elsevier using data from April 30, 2019. The CS of 2.40 ranks the journal in the 88th percentile (\#121) of 1038 education journals currently covered by Scopus (see https://www. 
scopus.com/sourceid/21100873488?origin=resultslist). Elsevier uses the following formula to calculate a journal's Scopus CiteScore, for example in 2019:

$$
\text { CiteScore }(C S)=\frac{\text { citations in } 2018 \text { to articles published in 2015-17 }}{\text { number of articles published in 2015-17 }}
$$

The CS of 2.40 means that each item published in the International Journal of STEM Education over the threeyear period from 2015 to 2017 was cited an average of 2.4 times in 2018 (or 180 citations in 2018 for 75 items published in 2015-17). This is a great achievement for a new journal, which clearly reflects the high quality of papers being published in this journal and their impact in academia. Because Scopus makes its calculation and all covered journals' CiteScores publicly available, readers can check and track the journal's on-going performance online at https://www.scopus.com/sourceid/211008734 88 ? origin $=$ resultslist.

The Web of Science's Social Sciences Citation Index (SSCI) uses a different process of evaluating a journal's performance, carried out by Clarivate Analytics that is independent from publishers. Before a journal being selected and covered in SSCI, it needs to be selected and accepted into the Web of Science's Emerging Sources Citation Index (ESCI) as the first step (Li, 2018a). The evaluation process typically involves multiple aspects, including journal publishing standards, editorial content, and international diversity, in addition to citation analysis as a key aspect (Testa, 2006). Clarivate Analytics also uses a formula, slightly different from CS computation, to calculate a journal's Impact Factor (IF) in 2019 as follows (https://clarivate.com/webofsciencegroup/essays/impact-factor/):

$$
\text { Impact Factor }(I F)=\frac{\text { citations in } 2018 \text { to articles published in 2016-17 }}{\text { number of articles published in 2016-17 }}
$$

Because the International Journal of STEM Education is now included in SSCI in 2019, the journal's citation performance in 2019 will become available for calculating its IF in 2020. We thus expect to receive the first IF in the mid of 2020, which will help us obtain another important and specific measure of the journal's performance, status, and impact in academia.

It should be noted that a journal's performance can be measured in many different ways, such as peer reviews, recognition in the field, authorship and readership development. In a recent editorial (Li, Froyd, \& Wang, 2019), we summarized and shared the journal's performance in its authorship and readership development. Interested readers can check that editorial to obtain further information.

\section{The status and development trends of the journal's publications over the years}

The International Journal of STEM Education has published a total of 51 items in its fifth publication cycle year (August 2018 to July 2019). Figure 1 shows the journal's growth in terms of the number of items published in each cycle year, from August 2014 to July 2019. It is clear that the journal has stabilized with an upward trend of publications over the years, with the same number of publications in the latest two publication cycle years (i.e., 51 publications in both the fourth and fifth publication cycles), in comparison to the prior three publication cycle years from August 2014 to July 2017 (i.e., 24, 21, and 22 in the first, second, and third cycles, respectively).

The journal publishes several types of items. Table 1 shows the breakdown of these 51 items published in the fifth publication cycle year by type, in comparison to the same breakdown of the 118 items published in the prior four cycle years from August 2014 to July 2018.

The types of publications present a consistent pattern over the years, with more than $75 \%$ publications as research articles. In the 2018 editorial (Li 2018a), I indicated that there is a noticeable shortage of research reviews. It is good to see that the journal published two research reviews in the fifth cycle year, which is equivalent to the number of research reviews published in the prior four cycle years as a whole. At the same time, two research reviews are accounted for only $4 \%$ of the

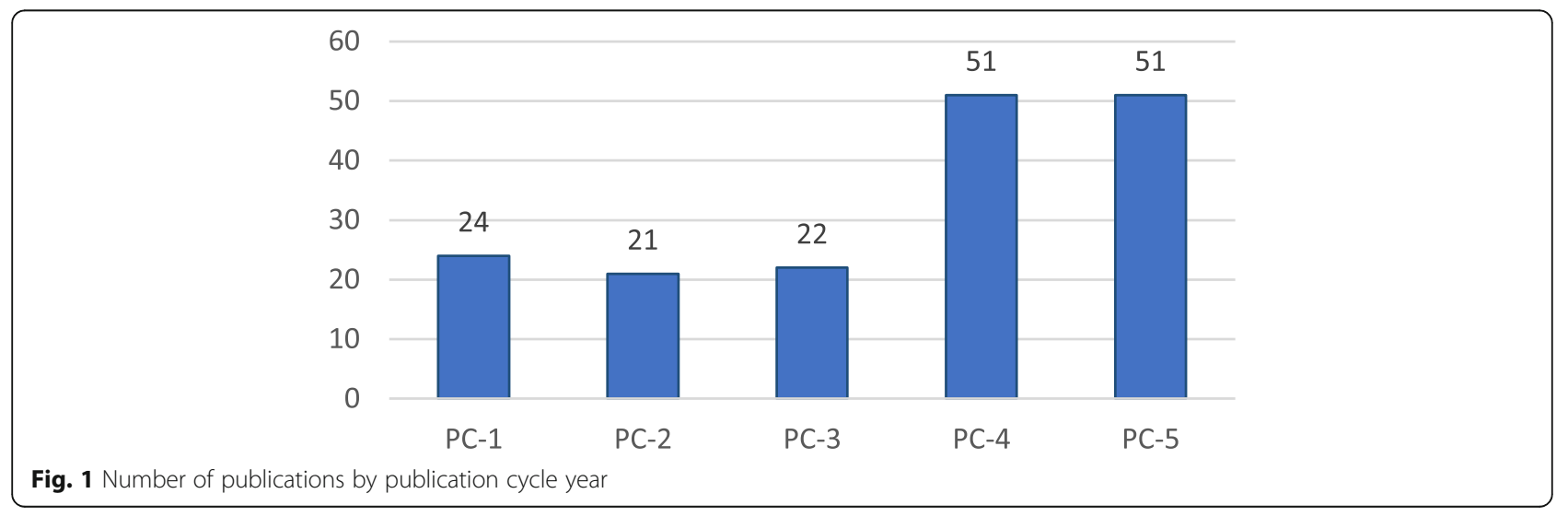


Table 1 Number (percentage) of publications of each type in the fifth publication cycle year in comparison to the prior four cycle years

\begin{tabular}{llllll}
\hline & Research articles & Research reviews & Short reports & Commentaries & Others $^{\text {a }}$ \\
\hline PCs 1-4 & $91(77 \%)$ & $2(2 \%)$ & $12(10 \%)$ & $8(7 \%)$ & $5(4 \%)$ \\
PC-5 & $39(76 \%)$ & $2(4 \%)$ & $2(4 \%)$ & $3(6 \%)$ & $5(10 \%)$ \\
\hline
\end{tabular}

Note: ${ }^{a}$ include editorials, guest editorials, and errata

publications in the fifth cycle year. Thus, it is important to note again that the journal certainly wants to encourage submission of many more research reviews.

Taking the same approach as in the 2018 editorial ( $\mathrm{Li}$, 2018a), we next examine publication distributions in terms of their disciplinary focuses. Figure 2 shows the percentage distribution of all publications in the fifth cycle year in comparison to the same breakdown of the 118 items published in the prior four cycle years: single(light color) vs. cross-discipline (dark color)

The results present a consistent pattern in terms of publications' disciplinary focuses between these two time periods. Overall, $64 \%$ of the publications have been cross-disciplinary, 36\% have been in an individual discipline. Represented among the latter are publications on education in a wide variety of individual disciplines, including biology, physics (when individual discipline in science is specified), science (when science is taken as a general discipline), mathematics, and engineering. For those publications in cross-disciplinary concentrations, readers can find publications on issues and questions that span across multiple disciplines, such as science, mathematics, and technology. These results again confirm that the journal is fulfilling its aim: to provide multidisciplinary perspectives needed to complement individual disciplinary-focused journals in STEM education $(\mathrm{Li}, 2014)$. At the same time, as stated before $(\mathrm{Li}$, $2014,2018 \mathrm{a}$ ), the journal will continue to value and welcome original contributions from different perspectives that view STEM education, either as a collection of traditionally defined, individual-disciplinary-based education separately in S.T.E.M. or as an educational undertaking in inter-connected STEM fields.

\section{The unique features of the International Journal of STEM Education, in comparison to other journals in STEM education}

The International Journal of STEM Education was established in 2014 as a multidisciplinary, open-access, peerreviewed research journal (Li, 2014). It distinguishes from many other journals in subject content education research in mutually complementary ways, such as those individual disciplinary-focused education journals in STEM and some other multi-disciplinary education journals that may focus on two- or three-disciplinary in STEM. The International Journal of STEM Education has been on its unique development path as an international gathering place for STEM disciplinary education scholars and readers (Li, 2018a).

In addition, the International Journal of STEM Education also differs from the Journal for STEM Education Research (STEM-ER), established in 2018 and also published by Springer (see https://www.springer.com/41 979). STEM-ER is designed as an interdisciplinary education research journal that is positioned as a pioneering research journal dedicated to developing interdisciplinary research in STEM education as a distinct field (Li, 2018b). Interested readers can check out recent publications in STEM-ER that Springer makes them available for free downloads in 2018 and 2019. It should be noted that STEM-ER also enjoyed significant access in its first year ( $\mathrm{Li}$ et al., 2019). The existence and

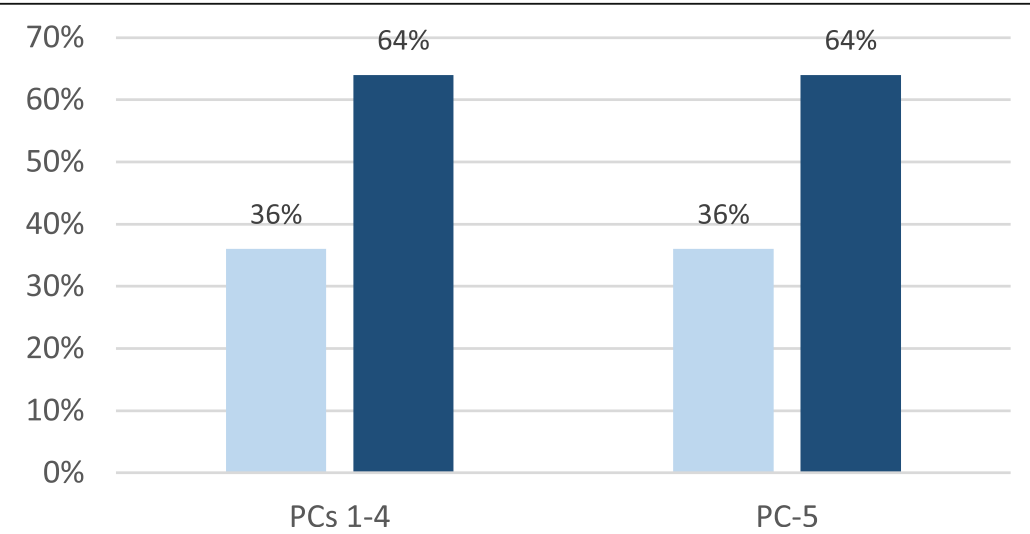

Fig. 2 Percentage of publications in single-disciplinary (light color bars) and cross-disciplinary (dark color bars) concentrations in the first four publication cycle years vs. the fifth publication cycle year 
success of these two different journals and some others in STEM education are important indications of the rapid growth of the international field of STEM education and the great need of the development and sharing of new and robust scholarship.

I want to take this opportunity to thank everyone for all the support and contribution to the journal. Without your strong and on-going support, this journal would not be able to go this far and fast. It is the contribution made by all authors, reviewers, members of the journal's editorial board, and staff members at SpringerOpen that allows the journal to pursue its quality commitment. It is the on-going visit to the journal to read and cite all the publications, done by all the researchers and readers in STEM education internationally, which helps the journal to fulfil its impact commitment. I sincerely hope the achievement of being covered in SSCI will serve as a starting point for the journal to help elevate the development of multidisciplinary STEM education to a new level.

\section{Acknowledgements}

The author would like to thank Marius Jung for his valuable feedback on an earlier version of this editorial.

\section{Author's contributions}

This work was conducted by a sole author

\section{Availability of data and materials}

The data and materials used and analyzed for the editorial were these articles published in this journal. They are publicly available at the journal's website (https://stemeducationjournal.springeropen.com)

\section{Competing interests}

Not applicable, as this is a single authored article.

Received: 22 November 2019 Accepted: 28 November 2019

Published online: 06 December 2019

\section{References}

Li, Y. (2014). International journal of STEM education - A platform to promote STEM education and research worldwide. Int J of STEM Educ, 1:1. https://doi. org/https://doi.org/10.1186/2196-7822-1-1.

Li, Y. (2018a). Four years of development as a gathering place for international researchers and readers in STEM education. Int J of STEM Educ, 5:54. https:// doi.org/https://doi.org/10.1186/s40594-018-0153-0.

Li, Y. (2018b). Journal for STEM education research - Promoting the development of interdisciplinary research in STEM education. Journal for STEM Education Research, 1(1-2), 1-6. https://doi.org/https://doi.org/10.1007/s41979-018-0009-z.

Li, Y., Froyd, J. E., \& Wang, K. (2019). Learning about research and readership development in STEM education: A systematic analysis of the journal's publications from 2014 to 2018. Int J of STEM Educ, 6:19. https://doi.org/ https://doi.org/10.1186/s40594-019-0176-1.

Testa, J. (2006). The Thomson scientific journal selection process. Int Microbiol, 9 $135-138$

\section{Publisher's Note}

Springer Nature remains neutral with regard to jurisdictional claims in published maps and institutional affiliations.

\section{Submit your manuscript to a SpringerOpen ${ }^{\circ}$ journal and benefit from:}

- Convenient online submission

- Rigorous peer review

- Open access: articles freely available online

High visibility within the field

- Retaining the copyright to your article

Submit your next manuscript at $\gg$ springeropen.com 